\title{
Efficacy and Safety of Intranasal Midazolam Versus Chloral Hydrate as Sedation for Quality Computed Tomography Imaging in Children
}

\author{
(1) Farhad Heydari1, (1) Hamid Shabani2 , (1) Saeed Majidinejad1', (1) Mohammad Nasr-esfahani \\ 1Isfahan University Medical of Sciences, Emergency Medicine Research Center, Alzahra Research Institute, Department of Emergency Medicine, \\ Isfahan, Iran \\ 2Isfahan University Medical of Sciences, Department of Emergency, Isfahan, Iran
}

\begin{abstract}
Aim: The purpose of this study was to compare the efficacy and safety of aerosolized intranasal midazolam (INM) compared to oral chloral hydrate $(\mathrm{OCH})$ as procedural sedatives in pediatric patients undergoing computed tomography $(\mathrm{CT})$ imaging.

Materials and Methods: A prospective, randomized, double-blind clinical trial was utilized in children aged 1 to 8 years who presented to the ED with minor head trauma and were scheduled to undergo brain CT scan. One hundred and sixty children were randomized to receive INM $0.3 \mathrm{mg} / \mathrm{kg}$ with oral placebo or $75 \mathrm{mg} / \mathrm{kg} \mathrm{OCH}$ with intranasal placebo. If the patient was not adequately sedated 20 minutes after the initial dose, a second dose of the same medication at one-third of the initial dosage was given. The sedation level of patients after drug administration was assessed using the Ramsay sedation scale.

Results: Both groups were comparable with respect to age, male to female ratio, weight, and baseline vital signs. Sixty two children (77.50\%) in the INM group and 59 children (73.42\%) in the OCH groups reached a Ramsay score of four, respectively $(p=0.55)$. There was no significant difference in regards to the time to become adequately sedated (21.32 \pm 6.54 vs $23.62 \pm 7.40, p=0.173)$ and time for completing CT scan (30.37 \pm 7.18 vs $32.96 \pm 7.85, p=0.185)$. However, the time to recovery was shorter for the INM group $(72.52 \pm 10.17$ vs $88.10 \pm 10.27$, $p=0.001)$. No serious side effects were seen in the study groups ( $p=0.836$ ). The majority of parents were somewhat to very satisfied, $83.54 \%$ and $81.25 \%$ in the OCH and INM groups, respectively $(p=0.928)$.

Conclusion: INM can be used to sedate children between 1 to 8 years who are to undergo CT imaging of brain with a comparable rate of efficacy and safety to $\mathrm{OCH}$.
\end{abstract}

Keywords: Chloral hydrate, computerized tomography, conscious sedation, intranasal midazolam

\section{Introduction}

In order to obtain useful data from accurate imaging without excessive radiation exposure, a child needs to be lain down during the scanning procedure. The imaging tests that are affected negatively by motion [computed tomography (CT) or magnetic resonance imaging] are the most common procedures for which children undergo sedation (1-3). Imaging can often be performed without sedation in older cooperative children and young infants (up to six months of age) who are swaddled and recently fed (1-4). It is difficult to keep younger children still during 
the time they need to get a scan. For CT, the child needs to lie still for 10-15 mins (3). There are several methods that can be used to limit the movement of a child during scanning.

Sedation has become more common for children undergoing imaging procedures. Adequate procedural sedation (PS) reduces patient's anxiety, reduces parental emotional distress and facilitates the ease, accuracy and the completion of the procedure $(1,4)$. When a child is kept still long enough to obtain the necessary imaging, a successful sedation is assumed (5). A wide range of sedative medications are available for pediatric procedural sedation and analgesia (PSA) $(6,7)$. The choice of drug and the targeted depth of sedation depends on the type of procedure and the patient's underlying medical condition (1-4). The ideal PSA agent should be one that has a quick onset of action, rapid recovery, few side effects, short and sufficient duration of action, provides airway protection, and has minimal effects on hemodynamics $(8,9)$. Effective sedation may be given by several routes: Intravenous (IV) and oral, rectal, intranasal, transcutaneous, intramuscular and inhalation.

Oral chloral hydrate $(\mathrm{OCH})$ is one of the first synthetic sedative agents, which has been considered as a sedative agent in pediatric patients for imaging, and it has been successfully given with other sedative agents (10-12). $\mathrm{OCH}$ produces effective sedation in $80-90 \%$ of patients (13). No significant adverse effects on cardiovascular or respiratory function have been reported at therapeutic doses $(12,14)$. The main disadvantage is gastric irritation, which can lead to vomiting.

Midazolam has become the benzodiazepine of choice in PSA, with a more rapid onset and offset of effect $(15,16)$. Midazolam is approved for many routes, including oral, IV, IM, rectal and intranasal (15-17). Intranasal Midazolam (INM) has got some advantages. INM can be rapidly absorbed through the highly vascularized nasal mucosa, resulting in a rapid and reliable onset of action. The shorter half-life, ease of administration, predictability and increased bioavailability by circumventing first-pass metabolism makes it a useful drug in the ED setting (17-21).

The dose of INM used in different studies range between $0.2 \mathrm{mg} / \mathrm{kg}$ and $0.5 \mathrm{mg} / \mathrm{kg}$. The most common adverse effects reported following INM are burning or irritation in the nose and a bitter taste in the mouth (1723). Aerosolized administration of midazolam on mucosal surfaces may enhance drug delivery. Aerosolized rather than drip administration of INM may decrease discomfort and improve tolerance of this route $(24,25)$.
In this study, we compared the efficacy, safety, and recovery time of aerosolized INM and $\mathrm{OCH}$ as procedural sedatives in pediatric patients undergoing $\mathrm{CT}$ imaging. We evaluated the successful sedation rate, time to achieve sedation, sedation duration, and side effects.

\section{Materials and Methods}

\section{Study Design and Setting}

This study was designed as a prospective, randomized, parallel group, double-blinded placebo-controlled clinical trial. The study was conducted between September 2017 and June 2018 at Al-Zahra and Kashani Hospitals, two university hospitals in Isfahan/Iran. This study was approved by the ethics committee of Isfahan University of Medical Sciences (approval number: IR.MUI.REC.1396.3.516) and was registered in the Iranian Registry of Clinical Trials under the number (IRCT20180129038549N4). Informed written parental consent was obtained before enrolling children into the study.

\section{Participants}

We enrolled a appropriate sample of children aged 1 to 8 years who presented to the ED with minor head trauma, were scheduled to undergo brain CT scan and who were determined by their physicians to require sedation. A complete history and physical examination determined all enrolled children as American Society of Anesthesiology class 1 (a normally healthy patient) or 2 (a patient with mild systemic disease e.g. mild asthma, controlled diabetes mellitus).

Children with any of the following criteria were excluded from the study: A history of developmental delay, underlying neurologic abnormality or autism; receiving a sedative hypnotic agent within the previous 48 hours; presence of gastritis or any other serious systemic disease; nasal allergy to drugs; obesity (body mass index >30), known contraindications to the use of the study drugs (e.g. hypersensitivity).

\section{Study Protocol}

We used a computer-generated random number table, which maintained allocation concealment, to randomize children into two groups. Randomization and double blinding of medication use was done by an independent investigator who was concealed from the study investigators. Neither the patients who received the drugs nor their parents, nor any of the investigators who administered the drugs, nor the health care providers knew the active component of the study medication. Data collectors and data analysts were all kept blinded to the allocation. 
After ensuring informed consent, the patient's demographics (weight, height, age, gender) were recorded. The patient's initial vital signs including respiratory rate $(\mathrm{RR})$, heart rate $(\mathrm{HR})$, and pulse oximetry $\left(\mathrm{O}_{2}\right.$ saturation) were documented.

The children were randomly divided into two groups: Namely the $\mathrm{OCH}$ group and the INM group. The $\mathrm{OCH}$ group received $75 \mathrm{mg} / \mathrm{kg} \mathrm{OCH}(100 \mathrm{mg} / \mathrm{mL}$, Merck KGaA Company, Germany) with $0.3 \mathrm{mg} / \mathrm{kg}$ of intranasal placebo and the INM group received $0.3 \mathrm{mg} / \mathrm{kg}$ INM $(5 \mathrm{mg} / \mathrm{mL}$, Tehran Shimi Company, Iran) with an oral $75 \mathrm{mg} / \mathrm{kg}$ placebo. The sedation level of the patients after drug administration was assessed using the Ramsay sedation scale (RSS) $(5,9,10,19)$. A score of four is considered as adequately sedated. If the patient was not adequately sedated 20 minutes after the initial dose, a second dose of the same medication at one third of the initial dosage was given. In case of failure to create an adequate sedation within 40 minutes, the patient was excluded from the study.

The RSS and vital signs (oxygen saturation, HR and RR) were examined at $10,15,20,25,30,40,60$ and up to 180 minutes as needed in the studied patients.

Placebos were prepared for INM and chloral hydrate syrup. Every child received both a spray and a syrup so that the chance of receiving either drug was equal. The drugs were prepared and packed by the pharmacist. Each package contained a nasal spray and syrup. The packets were marked A or B following the codes according to the randomization. In one packet, there were INM and oral placebo, and in another packet, there were an equal volume of chloral hydrate syrup and the intranasal placebo. The patients and their parents, nurses, health care providers, researchers, data collectors, and outcome assessors and data analysts were blind to the allocation.

\section{Outcome}

The primary outcome measurement was the efficacy to induce adequate sedation to complete the CT scan. Adequate sedation was determined by the study nurse or physician.

A secondary outcome was the side effects (oxygen saturation of less than 90\%, the need for assisted ventilation, vomiting, intractable irritability and agitation, laryngospasm, bradycardia and paradoxical agitation). The time from administration of the sedative drugs until adequate sedation, complete imaging and recovery criteria for discharge were also recorded. Recovery criteria included the return to baseline alertness, ability to maintain a patent airway, and the ability to sit up for 10 seconds or longer.

Parent satisfaction on a Likert scale (very satisfied, somewhat satisfied, unsure, somewhat dissatisfied, very dissatisfied) was evaluated by a study team member (19).

\section{Statistical Analysis}

Statistical analysis was performed using the SPSS 20.0 (IBM, Chicago, IL, USA). Chi-square test or Fisher exact test was used for data analysis of qualitative variables and mean values were compared using the independent t-test. All demographic and clinical variables were summarized using count and percentage $\mathrm{n}(\%)$ for categorical variables and means plus or minus standard deviations for continuous variables. $\mathrm{P}<0.05$ was determined to indicate statistical significance.

\section{Results}

One hundred and sixty children were entered into the study and 159 patients were analyzed. The patients of the two groups (INM and $\mathrm{OCH}$ ) had comparable age, male to female ratio, weight, and baseline vital signs (Table I). Sixtytwo children $(77.50 \%)$ in the INM group and 59 children $(73.42 \%)$ in the $\mathrm{OCH}$ groups reached a Ramsay score of four, respectively $(p=0.55)$. The acquired Ramsay sedation score was $3.95 \pm 0.618$ and $3.82 \pm 0.655$ in the INM and OCH groups respectively $(p=0.648)$ (Table II).

All children received an initial dose of medication, 33 $(41.25 \%)$ patients in the INM group and $29(36.71 \%)$ patients in the $\mathrm{OCH}$ group required a second dose $(p=0.627)$.

No difference was noted between the 2 study groups in regards to the time to become adequately sedated $(p=0.173)$ and time to completion of CT scan ( $p=0.185)$. However, the

Table I. Demographic and baseline characteristics of the children

\begin{tabular}{|c|c|c|c|}
\hline Characteristics & $\begin{array}{l}\text { Midazolam, } \\
n=80\end{array}$ & $\begin{array}{l}\text { Chloral } \\
\text { hydrate, } n=79\end{array}$ & $\mathrm{p}$ value \\
\hline Age (y) & $3.8500 \pm 1.72913$ & $3.8354 \pm 1.7572$ & 0.958 \\
\hline \multicolumn{4}{|l|}{ Sex } \\
\hline Male (\%) & $53(66.25 \%)$ & $51(64.56 \%)$ & \multirow{2}{*}{0.932} \\
\hline Female (\%) & $27(33.75 \%)$ & $28(35.44 \%)$ & \\
\hline Weight (kg) & $14.7750 \pm 3.63518$ & $14.2911 \pm 3.77628$ & 0.878 \\
\hline Heart rate, bpm & $105.33 \pm 16.84$ & $103.58 \pm 16.91$ & 0.513 \\
\hline Respiratory rate & $22.38 \pm 1.97$ & $23.24 \pm 2.04$ & 0.645 \\
\hline Oxygen saturation, \% & $98.63 \pm 0.93$ & $98.46 \pm 1.03$ & 0.334 \\
\hline
\end{tabular}


time to recovery was shorter for the INM group $(p=0.001)$ (Table II).

No serious side effects were seen in our study groups. Side effects including a decrease in $\mathrm{O} 2$ saturation $\geq 10 \%$ below baseline, vomiting, and paradoxical agitation were the same between the two groups $(p=0.836)$. The majority of parents were very to somewhat satisfied, $83.54 \%$ and $81.25 \%$ in the $\mathrm{OCH}$ and INM groups, respectively $(p=0.928)$ (Table II).

There was no need for any invasive resuscitation. Oxygen saturation, HR and RR showed no significant differences before and after sedation in both groups (Table III).

Table II. Comparison of primary and secondary outcomes

\begin{tabular}{|l|l|l|l|}
\hline Outcomes & Midazolam & $\begin{array}{l}\text { Chloral } \\
\text { hydrate }\end{array}$ & p value \\
\hline Adequately Sedated & $62(77.50 \%)$ & $59(73.42 \%)$ & 0.55 \\
\hline Second dose $^{1}$ & $33(41.25 \%)$ & $29(36.71 \%)$ & 0.627 \\
\hline $\begin{array}{l}\text { Acquired Ramsay } \\
\text { sedation score }\end{array}$ & $3.95 \pm 0.62$ & $3.82 \pm 0.66$ & 0.648 \\
\hline $\begin{array}{l}\text { Time to sedation } \\
\text { (minimum) }\end{array}$ & $21.32 \pm 6.54$ & $23.62 \pm 7.40$ & 0.173 \\
\hline $\begin{array}{l}\text { Time to completion of CT } \\
\text { scan (min) }\end{array}$ & $30.37 \pm 7.18$ & $32.96 \pm 7.85$ & 0.185 \\
\hline $\begin{array}{l}\text { Time to recovery } \\
\text { (minimum) }\end{array}$ & $72.52 \pm 10.17$ & $88.10 \pm 10.27$ & 0.001 \\
\hline Side effects ${ }^{1}$ & $10(14.28 \%)$ & $8(10.12 \%)$ & 0.836 \\
\hline Vomiting & $6(7.6 \%)$ & $6(7.6 \%)$ & - \\
\hline Decreased $\mathrm{O}_{2}$ saturation & $2(2.5 \%)$ & $2(2.5 \%)$ & - \\
\hline Paradoxical agitation & $2(2.5 \%)$ & $0(0 \%)$ & - \\
\hline Parental satisfaction ${ }^{1}$ & - & - & 0.928 \\
\hline Very satisfied & 25 & 27 & - \\
\hline Somewhat satisfied & 40 & 39 & - \\
\hline Unsure & 12 & 10 & - \\
\hline Somewhat dissatisfied & 3 & 2 & - \\
\hline Very dissatisfied & 0 & 1 & - \\
\hline
\end{tabular}

${ }^{1}$ Number (\%), ${ }^{2}$ Mean \pm standard deviation

\section{Discussion}

Appropriate sedation for children undergoing imaging in the ED is an important attribute for providing quality care and parental satisfaction. In this double blinded, placebo controlled randomized clinical study, the clinical effectiveness, safety, and potential side effects of $\mathrm{OCH}$ versus INM for pediatric sedation for brain $\mathrm{CT}$ scan were compared. The findings from this study show that $0.3 \mathrm{mg} /$ $\mathrm{kg}$ of INM has comparable efficacy to $75 \mathrm{mg} / \mathrm{kg}$ chloral hydrate orally for sedation in children between the ages of 1 year and 8 years who underwent imaging.

Adequate sedation was achieved in $77.50 \%$ of the children who used INM compared with $73.42 \%$ for those who were given $\mathrm{OCH}$. As in our study, Mekitarian Filho et al. (26) showed that the use of Aerosolized INM produced sedation in $76 \%$ of children within 20 minutes. Dallman et al. (27) showed an equal efficacy between INM $(0.2$ $\mathrm{mg} / \mathrm{kg}$ ) and chloral hydrate $(62.5 \mathrm{mg} / \mathrm{kg})$, although the latter caused longer sedation. However, Fallah et al. (5) showed that $\mathrm{OCH}$ was more effective than INM $(93.3 \%$ vs $40 \%$ ) in sedation induction in uncooperative children undergoing CT scan. The lower efficacy of midazolam in that study may be related to the low dose of $0.2 \mathrm{mg} / \mathrm{kg}$. Stephen et al. (21) concluded successful sedation leading to completion of procedure was achieved in $95 \%$ of children with chloral hydrate compared with $51 \%$ for INM. Probably the differences between individuals, race and age range of the patients led to these differences.

Our study demonstrates a faster recovery time with INM versus chloral hydrate, similar to studies by Wheeler et al. (28), and Dallman et al. (27) while in contrast to Stephen et al. (21) Dallman et al. (27) and Wheeler et al. (28) showed that patients sedated with INM slept less and recovered more quickly than patients sedated with $\mathrm{OCH}$, but Stephen et al. (21) showed that a significant difference in time to recovery was noted in the chloral hydrate group (78 minutes) versus the INM group (108 minutes).

The time to become adequately sedated and time to completion of $\mathrm{CT}$ scan was comparable between the 2

Table III. Comparison of physiologic parameters

\begin{tabular}{|l|l|l|l|l|l|l|}
\hline \multirow{2}{*}{ Parameter } & \multicolumn{3}{|c|}{ Before sedation } & \multicolumn{3}{c|}{ After sedation } \\
\cline { 2 - 7 } & Midazolam & Chloral hydrate & p value & Midazolam & Chloral hydrate & p value \\
\hline Heart rate, bpm & $105.33 \pm 16.84$ & $103.58 \pm 16.91$ & 0.513 & $104.38 \pm 15.12$ & $101.96 \pm 15.09$ & 0.313 \\
\hline Respiratory rate & $22.38 \pm 1.97$ & $23.24 \pm 2.04$ & 0.645 & $21.95 \pm 1.69$ & $22.74 \pm 1.78$ & 0.462 \\
\hline Oxygen saturation, \% & $98.63 \pm 0.93$ & $98.46 \pm 1.03$ & 0.334 & $98.12 \pm 0.80$ & $97.91 \pm 1.25$ & 0.523 \\
\hline
\end{tabular}

Bpm: beats per minute, values presented as mean \pm standard deviation 
groups in our study similar to the study by Wheeler et al. (28) Stephen et al. (21) demonstrated a faster onset of sedation with chloral hydrate versus INM. However, Fallah et al. (5) showed a faster onset with INM. These differences in studies can be due to differences in drug dosage or how they were administered. Midazolam by oral or intranasal routes achieves successful sedation in only 50 to 87 percent of patients undergoing $C T$, with higher efficacy in patients receiving it by the intranasal route $(15,16)$. Primosch and Guelmann (24), suggested that the use of a commercially available atomizer improved patient acceptance of INM administration but did not influence agent efficacy compared to drops administration for 2- to 3 -year-old dental patients in an office setting.

Hijazi et al. (29), showed that chloral hydrate $(75 \mathrm{mg} /$ $\mathrm{kg}$ ) compared to midazolam $(0.5 \mathrm{mg} / \mathrm{kg})$ had a higher sedation success rate, shorter time to achieve sedation, shorter length of stay in the hospital, and a longer sedation duration. Of course, oral midazolam has been compared in this study. Klein et al. (25), compared the administration of midazolam by 3 routes to facilitate pediatric laceration repair in the ED. They showed that $0.3 \mathrm{mg} / \mathrm{kg}$ INM produced superior sedation to identical doses via the buccal and oral routes with respect to time to onset, quality, and efficacy.

The dosages of medications used in this study were based on previous clinical literature and practice $(5,7,10,16)$. Several clinical trials report satisfactory sedation with either of these dosages $(5,21,29)$. Tsze et al. (18), determined the optimal volume of administration of INM sedation with escalating volumes of administration $(0.2,0.5$, and $1 \mathrm{~mL})$ during laceration repair in children in an ED. A volume of administration of $0.5 \mathrm{~mL}$ was associated with a statistically shorter time to onset of minimal sedation compared with a volume of administration of $1 \mathrm{~mL}$ or $0.2 \mathrm{~mL}$, but all 3 volumes of administration produced comparable clinical outcomes. The effectiveness of INM at a dose of $0.5 \mathrm{mg} / \mathrm{kg}$ in the conscious sedation of Iranian children was reported in another study (30).

Parents' average satisfaction with the sedative effect of INM in children was $81.25 \%$ and with the sedative effect of $\mathrm{OCH}$, it was equal to $83.54 \%$. Stephen et al. (21), and Fallah et al. (5) showed parents to be more satisfied with chloral hydrate $(p<0.01)$, while Wood (31) reported a higher score for INM.

In this study, INM and $\mathrm{OCH}$ were both found to be safe and effective drugs for sedation in children undergoing CT scan of the brain. No serious side effects were seen in our study groups.

\section{Study Limitations}

There are limitations to the study design that may have impacted the outcomes. The limitations of this study were the small number of patients enrolled and the short duration of follow up, further studies are needed to prove the effectiveness and compare the effects of these drugs.

This study was limited by the use of convenience sampling when the research team was available.

Increased nasal secretion due to the crying of the child following the drugs being sprayed into their nostrils could have diluted the effective dose of the delivered midazolam, thereby causing lower absorption rates. Also, it was observed that some of the drug is lost due to coughing, or dripping from the nares. Therefore, it is not possible to definitively determine the volume and dosage of INM that was delivered intranasally.

To make sure enough concealment, the study pharmacist prepared nasal midazolam using the IV dosage form of midazolam for all patients in the INM group. The effective dosage may not be comparable with available commercial intra nasal midazolam.

\section{Conclusion}

A dose of $0.3 \mathrm{mg} / \mathrm{kg}$ of INM, used for the sedation of those children between the ages of 1 to 8 years old who are to undergo CT imaging of brain, has as good an efficacy and safety profile as $75 \mathrm{mg} / \mathrm{kg}$ of $\mathrm{OCH}$. Compared with chloral hydrate, INM showed an earlier recovery. This study demonstrated that INM and $\mathrm{OCH}$ are equally effective for pediatric sedation and have comparable parental satisfaction.

\section{Ethics}

Ethics Committee Approval: This study was approved by the ethics committee of Isfahan University of Medical Sciences (approval number: IR.MUI.REC.1396.3.516).

Informed Consent: Informed written parental consent was obtained before enrolling children into the study.

Peer-review: Externally and internally peer-reviewed.

\section{Authorship Contributions}

Surgical and Medical Practices: F.H., S.M., M.N.E., Concept: F.H., Design: F.H., Data Collection or Processing: F.H., M.N.E., S.M., M.N.E., Analysis or Interpretation: F.H., M.N.E., H.S., Literature Search: F.H., M.N.E., S.M., M.N.E., Writing: F.H., M.N.E.

Conflict of Interest: The authors have no conflicts of interest relevant to this article to disclose. 
Financial Disclosure: The authors have no financial relationships relevant to this article to disclose.

\section{References}

1. Arlachov Y, Ganatra RH. Sedation/anaesthesia in paediatric radiology. Br J Radiol 2012;85:e1018-31.

2. Cravero IP, Blike GT, Beach $M$, et al. Incidence and nature of adverse events during pediatric sedation/anesthesia for procedures outside the operating room: report from the Pediatric Sedation Research Consortium. Pediatrics 2006;118:1087-96.

3. Bailey MA, Saraswatula A, Dale G, Softley L. Paediatric sedation for imaging is safe and effective in a district general hospital. Br J Radiol 2016;89:20150483.

4. Chokshi AA, Patel VR, Chauhan PR, Patel DJ, Chadha IA, Ramani $M N$. Evaluation of intranasal midazolam spray as a sedative in pediatric patients for radiological imaging procedures. Anesth Essays Res 2013;7:189-93.

5. Fallah R, Nakhaei MH, Behdad S, Moghaddam RN, Shamszadeh A. Oral chloral hydrate vs. intranasal midazolam for sedation during computerized tomography. Indian Pediatr 2013;50:233-5.

6. Kennedy RM, Luhmann JD. Pharmacological management of pain and anxiety during emergency procedures in children. Paediatric Drugs 2001;3:337-54.

7. Krauss B, Green SM. Procedural sedation and analgesia in children. Lancet 2006;367:766-80.

8. Macias CG, Chumpitazi CE. Sedation and anesthesia for CT: emerging issues for providing high-quality care. Pediatr Radiol 2011; 41:517-22.

9. Majidinejad S, Taherian K, Esmailian M, Khazaei M, Samaie V. Oral midazolam-ketamine versus midazolam alone for procedural sedation of children undergoing computed tomography; a randomized clinical trial. Emerg (Tehran) 2015;3:64-9.

10. Azizkhani R, Kanani S, Sharifi A, Golshani K, Masoumi B, Ahmadi O. Oral chloral hydrate compare with rectal thiopental in pediatric procedural sedation and analgesia; a randomized clinical trial. Emerg (Tehran) 2014;2:85-9.

11. Sahyoun C, Krauss B. Clinical implications of pharmacokinetics and pharmacodynamics of procedural sedation agents in children. Curr Opin Pediatr 2012;24:225-32.

12. Baxter AL, Mallory MD, Spandorfer PR, et al. Etomidate versus pentobarbital for computed tomography sedations: report from the Pediatric Sedation Research Consortium. Pediatr Emerg Care 2007;23:690-5.

13. Keim SM, Erstad BL, Sakles JC, Davis V. Etomidate for procedural sedation in the emergency department. Pharmacotherapy 2002;22:586-92.

14. Buck ML. A Monthly Newsletter for Health Care Professionals from the University of Virginia Children's Hospital. Pediatric Pharmacotherapy 2005;11.

15. Malviya S, Voepel-Lewis T, Prochaska G, Tait AR. Prolonged recovery and delayed side effects of sedation for diagnostic imaging studies in children. Pediatrics 2000;105:e42.

16. D'agostino I, Terndrup TE. Chloral hydrate versus midazolam for sedation of children for neuroimaging: a randomized clinical trial. Pediatr Emerg Care 2000;16:1-4.
17. Fantacci C, Fabrizio GC, Ferrara P, Franceschi F, Chiaretti A Intranasal drug administration for procedural sedation in children admitted to pediatric Emergency Room. Eur Rev Med Pharmacol Sci 2018;22:217-22.

18. Tsze DS, leni $M$, Fenster $D B$, et al. Optimal volume of administration of intranasal midazolam in children: a randomized clinical trial. Ann Emerg Med 2017;69:600-9.

19. Malia L, Laurich VM, Sturm J). Adverse events and satisfaction with use of intranasal midazolam for emergency department procedures in children. Am J Emerg Med 2018 Apr 30

20. Mellion SA, Bourne D, Brou L, et al. Evaluating Clinical Effectiveness and Pharmacokinetic Profile of Atomized Intranasal Midazolam in Children Undergoing Laceration Repair. J Emerg Med 2017;53:397-404

21. Stephen MC, Mathew I, Varghese AM, Kurien M, Mathew GA. A Randomized Controlled Trial Comparing Intranasal Midazolam and Chloral Hydrate for Procedural Sedation in Children. Otolaryngology Head Neck Surg 2015;153:1042-50.

22. Shapiro F, Athiraman U, Clendenin DJ, Hoagland M, Sethna NF. Anesthetic management of 877 pediatric patients undergoing muscle biopsy for neuromuscular disorders: a 20-year review. Pediatr Anesth 2016;26:710-21.

23. Conway A, Rolley I, Sutherland IR. Midazolam for sedation before procedures. Cochrane Database of Systematic Reviews. 2016;5:CD009491.

24. Primosch RE, Guelmann M. Comparison of drops versus spray administration of intranasal midazolam in two-and three-yearold children for dental sedation. Pediatr Dent 2005;5:401-8.

25. Klein E), Brown JC, Kobayashi A, Osincup D, Seidel K. A randomized clinical trial comparing oral, aerosolized intranasal, and aerosolized buccal midazolam. Ann Emerg Med 2011;58:3239.

26. Mekitarian Filho $E$, De Carvalho WB, Gilio AE, Robinson $F$ Mason KP. Aerosolized intranasal midazolam for safe and effective sedation for quality computed tomography imaging in infants and children. J Pediatr 2013;163:1217-9.

27. Dallman JA, Ignelzi MA, Briskie DM. Comparing the safety, efficacy and recovery of intranasal midazolam vs. oral chloral hydrate and promethazine. Pediatr Dent 2001;23:424-37.

28. Wheeler DS, Jensen RA, Poss WB. A Randomized, Blinded Comparison of Chioral Hydrate and Midazolam Sedation in Children Undergoing Echocardiography. Clin Pediatr 2001:40:381-7.

29. Hijazi OM, Ahmed AE, Anazi JA, Al-Hashemi HE, Al-Jeraisy Ml. Chloral hydrate versus midazolam as sedative agents for diagnostic procedures in children. Saudi Med I 2014;35:123-31.

30. Mazaheri R, Eshghi A, Bashardoost N, Kavyani N. Assessment of intranasal midazolam administration with a dose of $0.5 \mathrm{mg} /$ $\mathrm{kg}$ in behavior management of uncooperative children. J Clin Pediatr Dent 2008;32:95-9.

31. Wood M. The safety and efficacy of using a concentrated intranasal midazolam formulation for paediatric dental sedation. SAAD Dig 2011;27:16-23. 